\title{
Neue Richtlinien aus
} Arbeitskreisen

\section{AK Bewegungsapparat}

$\nabla$

Eine aktuelle Richtlinie zu den Stufenzertifizierungen und Weiterbildungsanforderungen steht auf der Website zur Verfügung.

\section{AK Qualitätssicherung \& Technik} $\nabla$

Eine Richtlinie zum Umgang mit Schallkopfproblemen \& -defekten, sowie eine Übersicht über Stand der Technik, Maßnahmen und Rechtslage stellt der AK auf seinen Webseiten zur Verfügung. 